archives-ouvertes

\title{
Nb-Doped TiO2 Nanofibers for Lithium Ion Batteries
}

Marcus Fehse, Sara Cavaliere, P.E. Lippens, Iuliia Savych, A. Iadecola, Laure

Monconduit, Deborah Jones, Jacques Roziere, Florent Fischer, Cécile Tessier, et al.

\section{To cite this version:}

Marcus Fehse, Sara Cavaliere, P.E. Lippens, Iuliia Savych, A. Iadecola, et al.. Nb-Doped TiO2 Nanofibers for Lithium Ion Batteries. Journal of Physical Chemistry C, American Chemical Society, 2013, pp.13827-13835. <10.1021/jp402498p > < <hal-00845155>

\section{HAL Id: hal-00845155 \\ https://hal.archives-ouvertes.fr/hal-00845155}

Submitted on 10 Feb 2014

HAL is a multi-disciplinary open access archive for the deposit and dissemination of scientific research documents, whether they are published or not. The documents may come from teaching and research institutions in France or abroad, or from public or private research centers.
L'archive ouverte pluridisciplinaire HAL, est destinée au dépôt et à la diffusion de documents scientifiques de niveau recherche, publiés ou non, émanant des établissements d'enseignement et de recherche français ou étrangers, des laboratoires publics ou privés. 


\title{
Nb-doped $\mathrm{TiO}_{2}$ Nanofibers for Lithium Ion Batteries
}

\author{
M. Fehse, ${ }^{* \dagger}$ S. Cavaliere, ${ }^{\dagger}$ P. E. Lippens,${ }^{\dagger}$ I. Savych,${ }^{\dagger}$ A. Iodacela,${ }^{\ddagger}$ L. \\ Monconduit, ${ }^{\dagger}$ D. J. Jones, ${ }^{\dagger}$ J. Rozière, ${ }^{\dagger}$ F. Fischer, ${ }^{\mathbb{I l}}$ C. Tessier, ${ }^{\mathbb{T l}}$ and L. Stievano*, ${ }^{\dagger}$ \\ ICG-AIME UMR 5253 Université Montpellier 2, CC 1502, Place E. Bataillon, 34095 Montpellier \\ Cedex 5, France, Elettra-Sincrotrone Trieste, Strada Statale 14, 34149 Basovizza, Italy., and \\ SAFT, Direction de la Recherche, 111-113 Bd Alfred Daney, 33074 Bordeaux, France \\ E-mail: marcus.fehse@univ-montp2.fr; lorenzo.stievano@univ-montp2.fr \\ Phone: +33 (0)4 671433 46. Fax: +33 (0)4 67143304
}

\begin{abstract}
Niobium doped nanofibers elaborated by facile, single-step electrospinning present higher rate capability in electrochemical cycling experiments than non-doped materials. This is attributed to the reduction of $\mathrm{Li}^{+}$diffusion path lengths and enhanced intimate inter-particle contact, in combination with improved intra-particle conductivity. Niobium doping has a significant effect on the electronic structure and provokes a substantial decrease in particle size.
\end{abstract}

\section{Introduction}

Since their introduction into the market in the early 90's by Sony, lithium ion batteries (LIB) have come a long way. ${ }^{1}$ Originally intended to serve only for small portable electronic devices, they have conquered numerous other fields of domestic and military applications and have become an

\footnotetext{
*To whom correspondence should be addressed

${ }^{\dagger}$ ICG-AIME Université Montpellier 2

ॠELETTRA Synchrotron

ISAFT Direction de la Recherche
} 
indispensable component of present day technologised society. Today LIB are at the dawn of entering not only the transportation market on the large scale but also to backbone the transition from fossil to renewable energy sources. In this development graphite, which is today's commercially established anode material, has limited high cycling rate properties due to necessary solid electrolyte interphase (SEI) formation and the risk of lithium plating when overcharged linked to its low working potential. An elevated performance is however crucial for application in the transportation sector, not only for rapid acceleration but also for reduced recharging times and recovery of braking energy. In the search of alternative anode materials $\mathrm{TiO}_{2}$ has been widely recognised as a viable candidate due to its cost effectiveness, environmental benignancy and lithium storage capability. Of particular interest is its tetragonal polymorph, the anatase phase. It has a high theoretical capacity $(335 \mathrm{mAh} / \mathrm{g})$, a flat operating potential and low volume expansion (ca. $3 \%$ ) during $\mathrm{Li}^{+}$charge/discharge leading to long cycle life and durability. ${ }^{2}$

However, the poor electronic conductivity (ca. $10^{-12}$ to $10^{-7} \mathrm{~S} / \mathrm{cm}$ ), the frequent aggregation of titania nanoparticles, and the low $\mathrm{Li}^{+}$diffusion rate (ca. $10^{-15}$ to $10^{-9} \mathrm{~cm}^{2} / \mathrm{s}$ ) reduce the electrochemical performance of anatase- $\mathrm{TiO}_{2}$. Considerable efforts have been made to overcome the ionic and electronic transport limitation of titania anodes. ${ }^{3-6}$ One approach is the tailoring of morphology and particle size of $\mathrm{TiO}_{2}$-based materials. In this respect, one dimensional (1D) nanostructured materials such as nanofibers and nanotubes are particularly interesting for LIBs, due to their large surface/volume ratio, their vectorial electron (along the long dimension) and $\mathrm{Li}^{+}$(along the lateral direction) transport properties, and their ability to accommodate lithiation-induced stresses. ${ }^{7,8}$

Soft-chemistry and template-based syntheses are usually employed to synthesise fibrous nanostructured electrodes, e.g. ${ }^{9-12}$ Among the methods for generating 1D nanostructures, electrospinning is a simple and versatile technique for preparing ultrathin nanofibers and nanotubes of polymers, ${ }^{13}$ composites ${ }^{14}$ and ceramics ${ }^{15}$ with controlled and reproducible diameters. Recent years have witnessed a growing development of electrospun $\mathrm{TiO}_{2}$-based electrodes for lithium-ion batteries, fuel cells and other conversion and energy storage devices. ${ }^{16-20}$

Various methods are pursued to further enhance the performance of electrospun titania when 
used as an active insertion material in LIB. One of them is the preparation of composite nanostructured electrodes interconnecting titania with a conducting additive nanophase (based on carbon), which improves the electron transfer. With this aim, porous carbon nanofibers loaded with $\mathrm{TiO}_{2}$ nanoparticles, ${ }^{21}$ composite $\mathrm{TiO}_{2} / \mathrm{C}^{22}$ and $\mathrm{TiO}_{2} /$ graphene nanofibers ${ }^{23}$ with improved reversible capacity and high rate behaviour have been recently reported. Another approach is surface modification to promote faster $\mathrm{Li}^{+}$diffusion and electron transport, but also to suppress particle agglomeration. ${ }^{24}$ For instance, the layer-by-layer self-assembly approach was combined with electrospinning for the fabrication of $\mathrm{MoO}_{2}$-modified $\mathrm{TiO}_{2}$ nanohybrids with improved lithium-storage properties, compared to the uncoated materials. ${ }^{19}$ A further approach to enhance the electrical conductivity of $\mathrm{TiO}_{2}$ nanofibers is by loading with metal nanoparticles. LIB anodes based on electrospun titania nanofibers embedding 10\% Au or Ag nanoparticles showed a $20 \%$ enhancement of the specific capacity and a 2 -fold rate performance compared to the bare $\mathrm{TiO}_{2} \cdot{ }^{25} \mathrm{TiO}_{2} / \mathrm{Ag}$ composite nanotubes fabricated by coaxial electrospinning also showed increased rate performance and cycling stability. ${ }^{26}$

Doping with aliovalent ions is also a facile strategy to modify the electronic properties of electrospun titanium oxide. ${ }^{17,18,27-30}$ Nevertheless, only few papers report this procedure for application of the materials in LIB. ${ }^{31}$ This is astonishing as, for example, Wang et al. show that the conductivity, which is the crucial parameter for high performance cycling, can be raised two orders of magnitude by doping mesoporous $\mathrm{TiO}_{2}$ with $\mathrm{Nb} .{ }^{32}$ These findings are in agreement with the results of Archana et al. stating an enhanced $\mathrm{Li}^{+}$mobility and diffusion coefficient for $\mathrm{Nb}$ doped $\mathrm{TiO}_{2}$ electrospun fibers ${ }^{33}$ as well as findings by Sheppard et al. describing metallic-type conduction behaviour of $\mathrm{Nb}$-doped $\mathrm{TiO}_{2} \cdot{ }^{34}$

In the present paper we report the synergistic effects of nanostructuring by electrospinning and doping with niobium on $\mathrm{TiO}_{2}$ anode materials for lithium-storage applications. Nanofibrous $\mathrm{TiO}_{2}$ with and without $\mathrm{Nb}$ doping are synthesised via electrospinning and characterised via XRD, SEM and XAS. Furthermore we provide results from DFT calculations to explain in detail the effect of $\mathrm{Nb}$ doping on electronic band structure, explaining the observed increase of the electronic 
conductivity. The potency of the nanofibers as lithium insertion material was tested by preparing film electrodes and applying them in half-cells vs. lithium. Simple, standardized synthesis and electrode preparation method were chosen to elucidate only the effect of $\mathrm{Nb}$-doping on the electrochemical cycling properties, avoiding possible pseudocapacitive storage contribution from morphology tailoring or enhanced conductivity by elaborated electrode formulation, as such might superimpose to the effects of the dopant and hence disguise its benefits.

\section{Experimental}

\section{Synthesis of $10 \% \mathrm{Nb}$-doped and non-doped $\mathrm{TiO}_{2}$ nanofibers}

The detailed synthesis of titania nanofibers has already been reported elsewhere. ${ }^{17}$ Briefly, the carrier polymer solution based on polyvinyl pyrrolidone (average $\mathrm{Mw} \approx 1,300,000 \mathrm{~g} / \mathrm{mol}$, Aldrich) in absolute ethanol (puriss., Sigma-Aldrich) was mixed with a solution containing $0.52 \mathrm{ml}$ of titanium(IV)isopropoxide (97\%, Aldrich), (and $0.040 \mathrm{ml}$ of niobium ethoxide, $99.95 \%$, Aldrich) and $1 \mathrm{ml}$ of acetic acid (Sigma-Aldrich), corresponding to a dopant content of $10 \mathrm{at} \%$. Electrospinning of the final solution was carried out in air at room temperature with a standard syringe and a grounded collector plate configuration. The distance between the needle tip and the collector plate was $10 \mathrm{~cm}$, the applied voltage $15 \mathrm{kV}$ and the flow rate $0.5 \mathrm{ml} / \mathrm{h}$. The as-prepared fibers were calcined in air at $500{ }^{\circ} \mathrm{C}$ at a heating rate of $5^{\circ} \mathrm{C} / \mathrm{min}$ for 6 hours in order to remove the carrier polymer.

\section{Electrode and cell preparation}

For electrochemical measurements, the titania powder which serves as active insertion material was mixed with carbon black and PVdF with a weight composition of 80:8:12, respectively. An NMP-based slurry of this mixture was tape casted on a copper foil using a doctor blade system leading to homogeneous $\approx 25 \mu \mathrm{m}$ thick films which were cut and used as working electrodes. 
These were built in Swagelok cells together with lithium metal as reference and counter electrode as well as Whatman fiber glass separators. A standard mixture of organic solvents containing ethylene carbonate, propylene carbonate and dimethyl carbonate in composition 1:1:3 and $1 M$ $\mathrm{LiPF}_{6}$ was used as the electrolyte. Since both electrolyte and lithium metal are very sensitive to air and moisture, the assembly of the electrochemical cells was carried out in a glove box under Ar atmosphere.

\section{Characterization}

The nanofiber morphology was verified by using a scanning electron microscope (SEM) Hitachi $S$-4800 FEG equipped with energy-dispersive spectroscopy analysis (EDS) and a JEOL 1200 EXII transmission electron microscope (TEM) operating at $120 \mathrm{kV}$ equipped with a CCD camera SIS Olympus Quemesa (11 million pixels). The crystal structures were identified by powder X-ray diffraction (XRD) using a Philips X'pert diffractometer with $\mathrm{Cu} \mathrm{K}_{\alpha}$ radiation at room temperature, in the range from $10-70^{\circ} 2 \Theta$ using a step size of $0,026^{\circ}$ and dwell time of 3500 sec. Fullprof was used for determination of unit cell parameters (Rietveld refinement). Nitrogen physisorption was carried out on a Micromeritics ASAP2020 and the adsorption and desorption isotherms were analyzed using Brunauer-Emmett-Teller (BET) as well Density Functional Theory (DFT) methods to calculate specific surface area and pore size distribution, respectively.

The surface composition of the non-doped and $\mathrm{Nb}$-doped $\mathrm{TiO}_{2}$ fibers was monitored by $\mathrm{X}$-ray photoelectron spectroscopy (XPS) on an ESCALAB 250 (Thermo Electron). The X-ray excitation was provided by a monochromatic $\mathrm{Al} \mathrm{K}_{\alpha}(1486.6 \mathrm{eV})$ source with a beam diameter of $400 \mu \mathrm{m}$. A constant analyzer energy mode was used for the electron detection ( $20 \mathrm{eV}$ pass energy). The detection of the emitted photoelectrons was performed perpendicularly to the sample surface. Data quantification was performed on the Avantage program. The background signal was removed using the Shirley method. The surface atomic concentrations were determined from photoelectron peaks areas using the atomic sensitivity factors reported by Scofield. Binding energies (BE) of all core levels were referred to the $\mathrm{C}-\mathrm{C}$ bond of $\mathrm{C} 1 \mathrm{~s}$ at $284.8 \mathrm{eV}$. 
Raman spectroscopy was carried using LabRam ARAMIS IR ${ }^{2}$, Horiba Jobin Yvon with blue diode laser $\lambda=473 \mathrm{~nm}$ or helium neon laser $\lambda=633 \mathrm{~nm}$.

XAS measurements were carried out at ambient temperature on the beamlines A (HASYLAB @ DESY, Hamburg, Germany) and XAFS (ELETTRA, Trieste, Italy). The Ti K-edge spectra were recorded in transmission mode on homogeneous pressed pellets of adequate thickness. Fourier transform were performed using $\mathrm{k}^{2}$ weighting and the structural parameters were determined by curve-fitting procedures using Artemis data analysis software with embedded FEFF tool for calculating scattering paths on the basis of the anatase structure. To fit Nb-doped anatase in the R-space, FEFF paths based on $\mathrm{Nb}_{2} \mathrm{O}_{5}$ crystal structure in which the central $\mathrm{Nb}$ atom was exchanged for $\mathrm{Ti}$ were added, in order to include Ti-Nb bonds in the calculations.

Electronic structure calculations based on DFT and a generalized gradient approximation (GGA) using an exchange-correlation potential by Perdew, Burke and Ernzerhof ${ }^{35}$ were performed for anatase $\mathrm{TiO}_{2}$ and three supercells of 24 atoms $\left(\mathrm{NbTi}_{7} \mathrm{O}_{16}\right), 48$ atoms $\left(\mathrm{NbTi}_{15} \mathrm{O}_{32}\right)$ and 108 atoms $\left(\mathrm{NbTi}_{35} \mathrm{O}_{72}\right)$ which correspond to $\mathrm{Nb}$ doping of about $12 \%, 6 \%$ and $3 \%$, respectively. The augmented plane-wave method + local orbital $(\mathrm{APW}+\mathrm{lo})$ as implemented in the WIEN2k code ${ }^{36}$ was used with the muffin-tin $\operatorname{radii} \operatorname{Rmt}(\mathrm{Ti})=2.0$ a.u., $\operatorname{Rmt}(\mathrm{O})=1.4 a \cdot u$. and $\operatorname{Rmt}(\mathrm{Nb})=2.0$ a.u., the semicore states: Ti 3s, Ti 3p, O 2s, $\mathrm{Nb} 4 \mathrm{~s}$ and $\mathrm{Nb} 4 \mathrm{p}$, the plane-wave cutoff: $\min (\mathrm{Rmt}) \cdot \max (\mathrm{K})=7$ (where $\mathrm{K}$ is a reciprocal lattice vector) and the magnitude of the largest vector in the charge-density Fourier expansion: $\mathrm{Gmax}=15 R y^{-1 / 2}$. The experimental values of the lattice constants were used for the calculations but the internal atomic positions were moved in order to minimize the internal atomic forces. A similar approach was successfully used for the electronic structure calculations of $\mathrm{Sn}^{37}$ and $\mathrm{Zr}^{38}$ doped anatase $\mathrm{TiO}_{2}$. Self-consistency was achieved with an energy tolerance of $10^{-4} R y$ and a force tolerance of $10^{-3} R y \mathrm{Bohr}^{-1}$. The XAS spectra were calculated from the dipole transition strengths and the partial density of states (PDOS) in the same way as previous calculations for $\mathrm{Li}_{4} \mathrm{Ti}_{5} \mathrm{O}_{12} .{ }^{39}$ The calculated Ti K-edge spectra were averaged over all the Ti atoms of the supercells. For comparison with experiments the calculated spectra were convoluted with a Lorentzian function $(\mathrm{FWHM}=2 \mathrm{eV})$. 
The electrochemical cycling was carried out in galvanostatic mode on a Biologic multichannel potentiostat. Different cycling rates were applied ranging from $\mathrm{C} / 20$ to $5 \mathrm{C}$ whereas $1 \mathrm{C}$, corresponds to the insertion of $1 \mathrm{Li}$ per hour into $\mathrm{TiO}_{2}$ which is equal to a current of $336 \mathrm{~mA} / \mathrm{g}$.

\section{Results}

\section{Electrode properties and electrochemical characterization}

Film electrodes were prepared via tape casting of slurry made of $\mathrm{Nb}$-doped or non-doped $\mathrm{TiO}_{2} / \mathrm{C} / \mathrm{PVdF}$ mixture which resulted in homogeneous, uniform and smooth film electrodes with a loading of $\mathrm{Nb}$ doped or non-doped $\mathrm{TiO}_{2}$ of roughly $1.5 \mathrm{mg} / \mathrm{cm}^{2}$. Energy dispersive X-ray spectroscopy (EDS) analysis of such electrodes reveals a homogeneous distribution of active insertion material $\mathrm{TiO}_{2}$ and dopant Nb, see Fig. 1(b) and (c) respectively. Furthermore a Nb content of $8.1 \pm 0.2$ at\% is determined from the ratio of $\mathrm{Ti} / \mathrm{Nb}$. This is close to the aspired value of $10 \mathrm{at} \%$, while at the same time no unexpected elements were detected. EDS has a penetration depth of $\approx 10 \mu \mathrm{m}$, assuring that the here stated value can be considered as the bulk concentration.
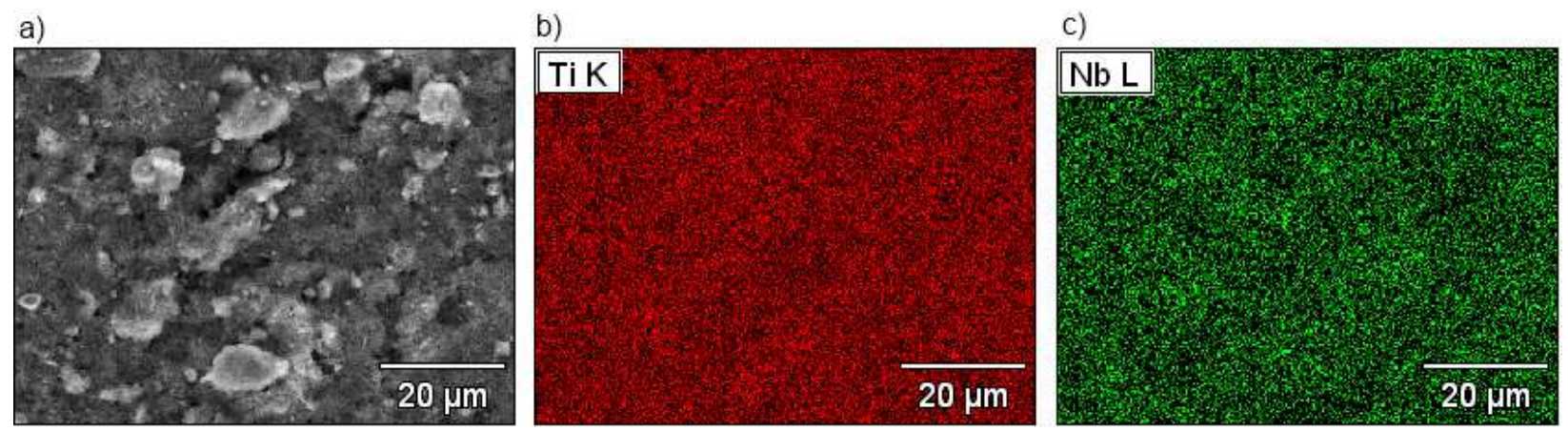

Figure 1: a) EDX image and b) elemental mapping of $\mathrm{Ti}$ and c) of $\mathrm{Nb}$ of tape casted film electrode.

The galvanostatic cycling curve for the first cycle with doped and non-doped $\mathrm{TiO}_{2}$ electrodes are presented in Fig. 2(a). The curves are quite similar, revealing typical insertion behaviour of nanoscaled anatase with a plateau at $1.75 \mathrm{~V}$ which is followed by a slope which correspond to the biphasic and subsequent monophasic lithium insertion mechanism, respectively. It is noteworthy that the irreversible voltage plateau is less pronounced for the $\mathrm{Nb}$-doped sample. In the first cycle a 
high irreversibility is observed which suggests a SEI formation and trapping of $\mathrm{Li}^{+}$in irreversible sites. The samples were cycled 20 cycles at subsequently increased cycling rate and the mean values of each cycling rate are presented in 2(b). Similar average capacity values at low cycling rates $\mathrm{C} / 20$ and $\mathrm{C} / 5$ are obtained for doped and non-doped $\mathrm{TiO}_{2}$, see Fig. 2(b) 140 vs. $128 \mathrm{mAh} / \mathrm{g}$ and 97 vs. $92 \mathrm{mAh} / \mathrm{g}$, respectively. However, as the cycling rate is increased, a growing difference between the capacities obtained for doped and non-doped $\mathrm{TiO}_{2}$ electrodes appears, while no general difference between the galvanostatic cycling curves is observed (not shown here). Although the overall capacity values are well below those found by Wang et al. (142 and $108 \mathrm{mAh} / \mathrm{g} @ \mathrm{C} / 4$ and $1 C$, respectively for mesoporous $\mathrm{Nb}$-doped $\mathrm{TiO}_{2}$ with $\left.128 \mathrm{~m}^{2} / \mathrm{g}\right)^{32}$ the direct comparison of non-doped and $\mathrm{Nb}$-doped material reveals a superior high rate capability of the $\mathrm{Nb}$-doped sample. At highest cycling rate $5 C$ the doped samples achieve double the capacity of non-doped $\mathrm{TiO}_{2}, 23$ vs. $10 \mathrm{mAh} / \mathrm{g}$. This phenomena of increased rate capability while maintaining absolute capacities was also recently reported for $\mathrm{N}$-doped $\mathrm{TiO}_{2}$ fibers. ${ }^{31}$
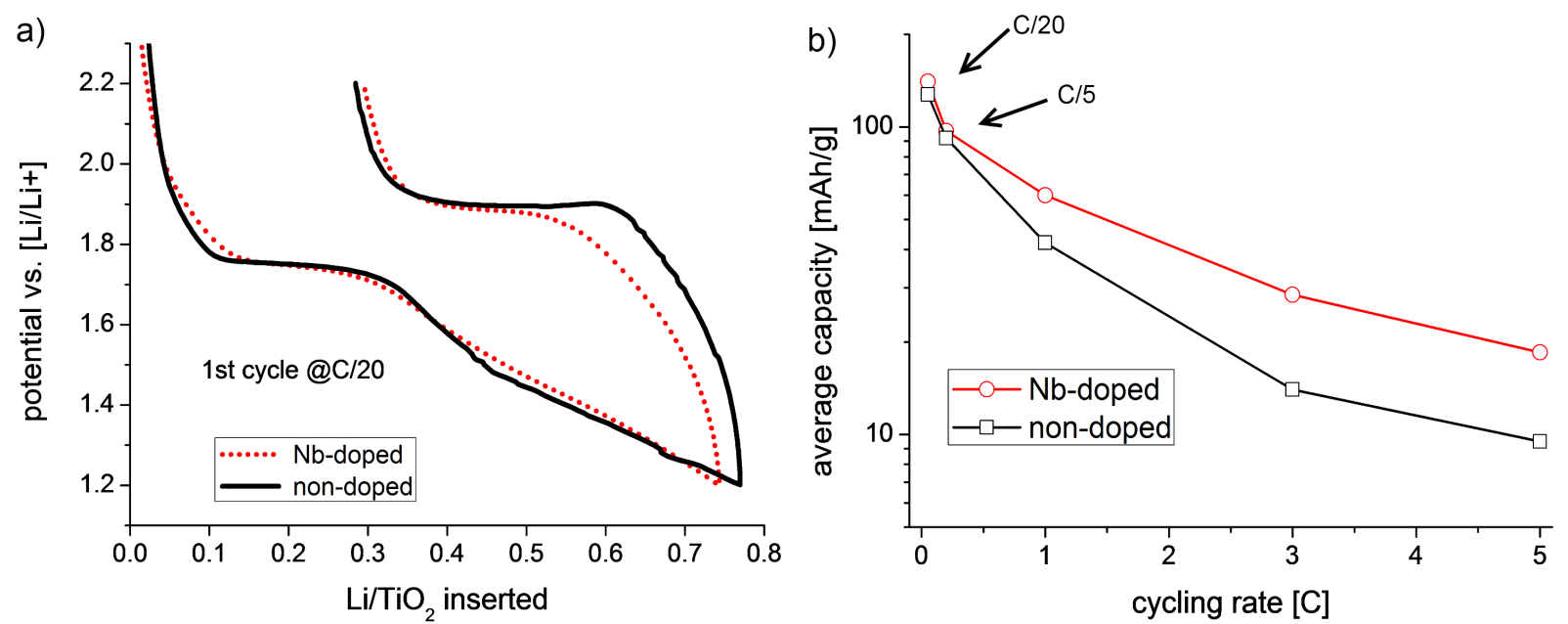

Figure 2: Comparison of a) galvanostatic cycling curve and b) mean rate capability of non-doped and $\mathrm{Nb}$-doped electrospun $\mathrm{TiO}_{2}$ nanofiber electrodes.

In order to elucidate the reason for this significant improvement in rate capability a series of characterization techniques and calculations were performed which illuminate the diverse influence of $\mathrm{Nb}$ doping on electrospun $\mathrm{TiO}_{2}$ fibers. 


\section{Morphology}

In Fig. 3(a) the SEM and (c) TEM micrographs show the morphology of the electrospun Nb-doped $\mathrm{TiO}_{2}$ nanofibers. Uniform polycrystalline fibers with average diameter of $51 \pm 19 \mathrm{~nm}$ are obtained whereas the length can reach several micrometers. Note that the TEM contrast variations reflect the polycrystalline microstructure of the fibers, consisting of well grown nanocrystals with different orientations. The graph in Fig. 3(b) shows the diameter distribution revealing the conformity of the nanofiber morphology, with $\geq 95 \%$ of all values falling into the narrow of range $20-80 \mathrm{~nm}$. SEM and TEM of non-doped $\mathrm{TiO}_{2}$ show an equally narrow fiber distribution of diameter with a slightly higher average diameter of about $62 \mathrm{~nm}$ (not presented here). This small difference agrees with our previous observations ${ }^{17}$ and with the findings by Archana et al. ${ }^{33}$ but is in opposition to the results of $A n$ and $A h n,{ }^{40}$ who showed rather a slight increase in the diameter of the fibers on $\mathrm{Nb}$ doping. It should be pointed out though that in any of these cases the magnitude of changes in diameter is small.

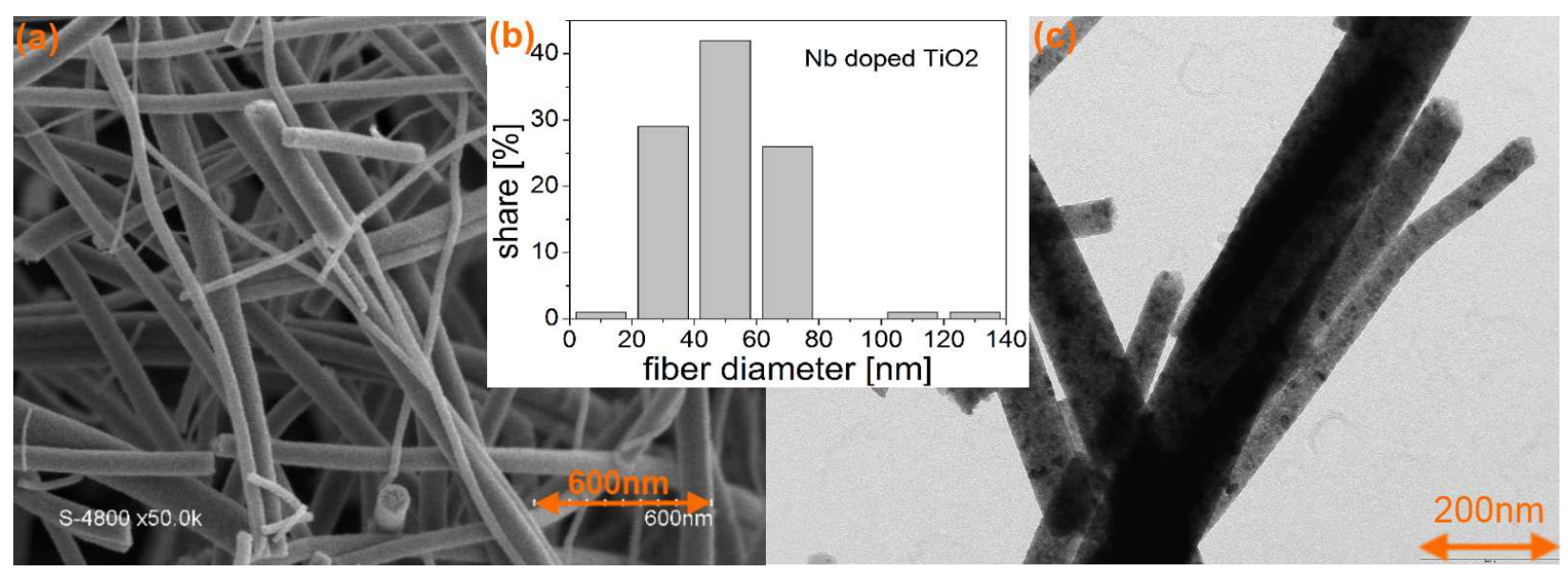

Figure 3: (a) SEM and (c) TEM micrographs of $\mathrm{Nb}$-doped electrospun $\mathrm{TiO}_{2}$ nanofibers and (b) distribution of fiber diameter.

The results of nitrogen physisorption reveal also a great conformity of doped and non-doped samples. A type IV physisorption isotherm ${ }^{41}$ is observed which indicates mesoporosity, and BET specific surface area of 66 and $44 \mathrm{~m}^{2} / \mathrm{g}$ for doped and non-doped sample, respectively was determined (not shown). We attribute this gain in specific surface area mainly to the reduced grain size, 
as pointed out in Sec. . The similarity of the results is in agreement with the assumption that $\mathrm{Nb}$ doping has no significant influence on the global morphology of $\mathrm{TiO}_{2}$ electrospun nanofibers, as shown in previous work. ${ }^{17}$

\section{Crystal structure}

When comparing crystal and local structure of doped and non-doped samples by XRD and Raman spectroscopy, (Fig. 4) we find a clear signature of anatase phase of both samples and no visible segregation of possible Nb-containing phases. While Raman spectra Fig. 4(b) reveals a single anatase phase, the XRD patterns Fig. 4(a) shows very minor traces of rutile as well as brookite in both samples, which is coherent with previous findings. ${ }^{17}$ The discrepancy between these two results is due to the lower sensitivity of Raman spectroscopy compared to XRD. In the XRD patterns we find besides a peak broadening, corresponding to a crystallite size reduction from 15 to $7 \mathrm{~nm}$ determined using the Scherrer equation, a slight but significant peak shift to lower diffraction angles for the $\mathrm{Nb}$-doped samples. According to Ruiz et al. Nb doping obstructs grain coarsening, which Guidi et al. attribute to the reduced ionic oxygen mobility. ${ }^{42,43}$ The XRD peak shift corresponds to an increase of lattice parameter $a(3.789 \AA$, ICSD009853) of $\approx 0,014 \AA$ equivalent to $\approx 3.7 \%$ o. Whether this expansion is due to larger ionic radius of $\mathrm{Nb}^{5+}(0.64 \AA)$ compared to that of $\mathrm{Ti}^{4+}(0.61 \AA)$, or a strengthening in Coulombic repulsion force between $\mathrm{Nb}$ and $\mathrm{Ti}$ cannot be answered at this point with certainty. Our findings are in agreement with the general idea of lattice expansion through substitutional doping of $\mathrm{Ti}$ by $\mathrm{Nb}$, except that the magnitude of expansion is somewhat smaller than those found in the literature. ${ }^{40,42,44,45}$ This is likely to be related to the influence of the nanostructuring on the lattice parameter which already accounts for an expansion of $\approx 2.4 \%$ ocompared to reference value. ${ }^{46}$

The Raman spectra show exclusively the typical bands of anatase, Fig. 4(b). A closer look reveals however small differences in the $\mathrm{Nb}$-doped $\mathrm{TiO}_{2}$ spectra. Not only a blue shift of the characteristic $E_{g}$ band by $\approx 1 \mathrm{~cm}^{-1}$ from the reference value of $144 \mathrm{~cm}^{-147}$ is observed, but also a deformation of the line shape. This asymmetry might result from the sum of a distribution of 
peaks reflecting a slight inhomogeneous $\mathrm{Nb}$ distribution. In addition the creation of defects through doping is contributing to the observed peak broadening. The $\mathrm{E}_{g}$ band corresponds to the O-Ti-O bending vibration. If applying the harmonic oscillator model, the exchange of Ti for heavier $\mathrm{Nb}$ atom should lead to a shift to lower wavenumber unless this change in mass is compensated by increased binding energy. Using the example of substitutional doping of Ti by $\mathrm{Zr}$ in $\mathrm{TiO}_{2}$ Lejon and Österlund attributed the observed Raman blue shift to surface stresses as well as spatial phonon confinement effects linked to Zr-doping induced decrease of particle size, while at the same time an expansion of the lattice parameter is observed. ${ }^{48}$ Ruiz et al. have described a direct relation between Raman line shift and expansion of lattice parameters, which substantiates the insertion of $\mathrm{Nb}$ dopant in $\mathrm{TiO}_{2}$ lattice; ${ }^{42}$ analogous results are published by Babu et al. for substitution of oxygen by $\mathrm{N}$ dopant in $\mathrm{TiO}_{2} \cdot{ }^{28}$
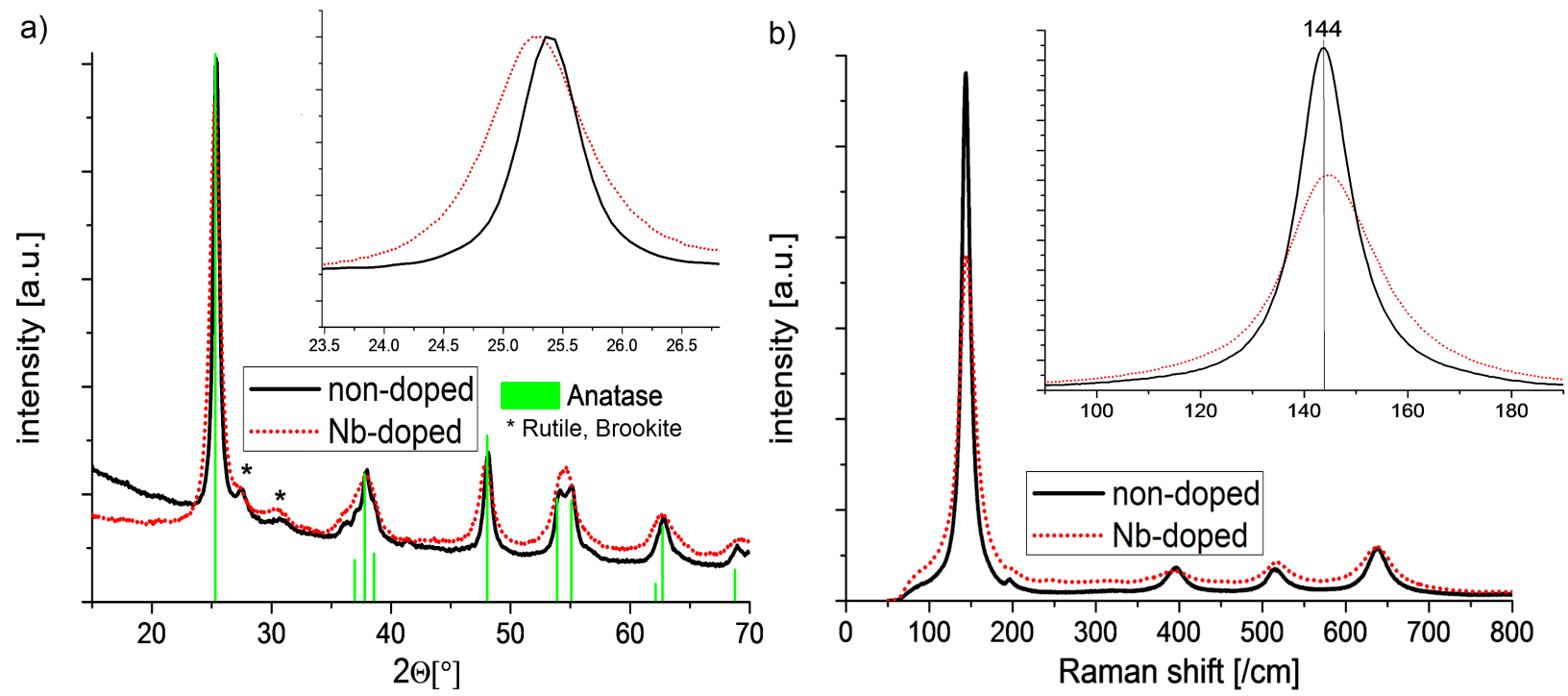

Figure 4: a) XRD diffractogram with anatase reference [ICSD 009853] and b) Raman spectra comparison of non-doped and $\mathrm{Nb}$-doped $\mathrm{TiO}_{2}$ nanofibers, showing the complete survey and an enlarged cut out of most intense signal.

\section{Surface composition analysis}

Since the structural characterization does not provide sufficient proof of $\mathrm{Nb}$ presence in the $\mathrm{TiO}_{2}$ lattice XPS measurements were carried out. XPS spectra of the nanofibers are presented in Fig. 
5(a) showing characteristic $\mathrm{Nb} 3 \mathrm{~d}$ twin peaks for the $\mathrm{Nb}$-doped sample and in Fig. 5(b) comparison of Ti $2 p$ signals for non-doped and $\mathrm{Nb}$-doped $\mathrm{TiO}_{2}$ nanofibers. Ti $2 \mathrm{p}_{1 / 2}$ and $\mathrm{Nb}_{3} \mathrm{~d}_{3 / 2}$ peaks appear at 458.7 and $207.2 \mathrm{eV}$, respectively, indicating that titanium is present as $\mathrm{Ti}^{I V+}$ and niobium as $\mathrm{Nb}^{V+}$. No sign of $\mathrm{Ti}^{I I I+}\left(455 \mathrm{eV}^{49}\right)$ or $\mathrm{Nb}^{I V+}\left(205.9 \mathrm{eV}^{50}\right)$ are visible in the spectra. These results foster the assumption that an effective aliovalent doping is accomplished. Furthermore we can deduct that charge compensation of $\mathrm{Nb}^{V+}$ is not achieved by reducing $\mathrm{Ti}^{I V+}$ to $\mathrm{Ti}^{I I I+}$ but more likely producing oxygen vacancies in the anatase lattice. It is nevertheless noteworthy that when interpreting XPS data of doped, high specific surface area, nanostructured samples one has to take due care as surface state effects, change in Fermi level position and band bending are influencing the peak position. ${ }^{5,42,51}$
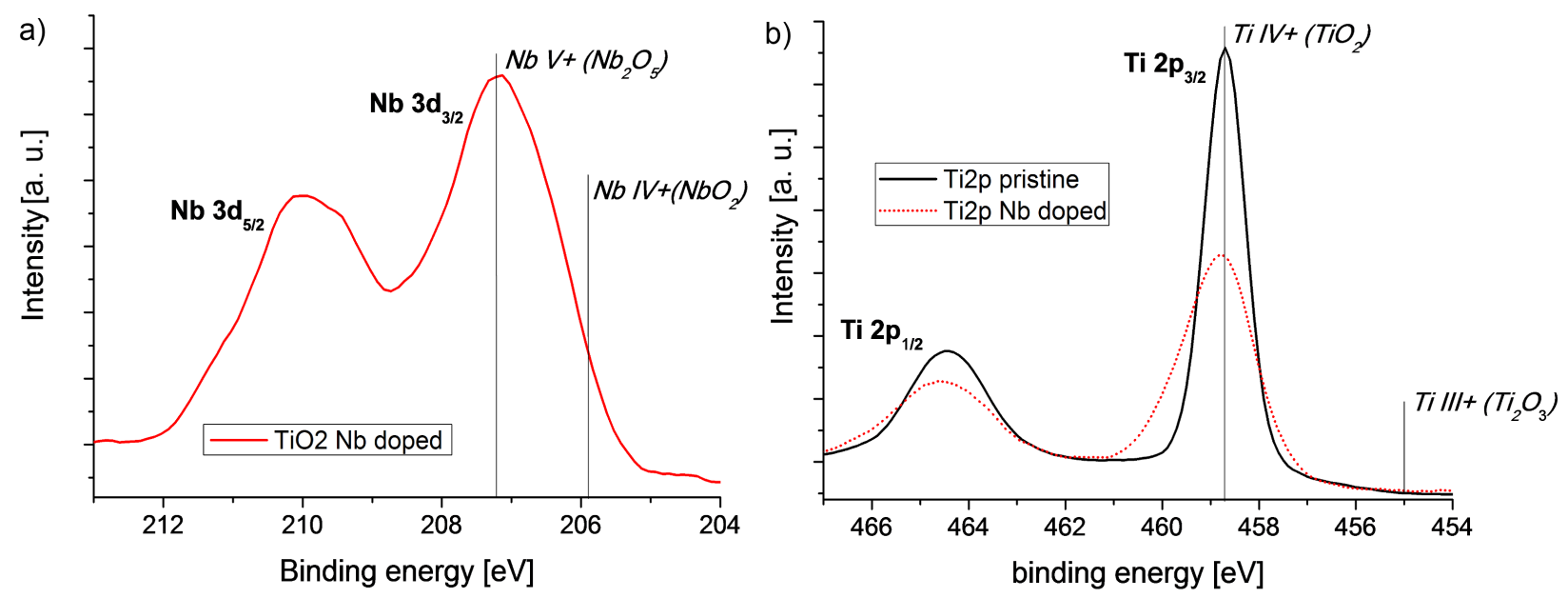

Figure 5: XPS spectra a) $\mathrm{Nb} 3 \mathrm{~d}$ peaks and b) Ti 2p peaks comparison of doped and non-doped electrospun $\mathrm{TiO}_{2}$ nanofibers.

From quantification measurements we obtained a $\mathrm{Nb}$-to-Ti ratio of $\approx 16 \%$ which denotes a slight agglomeration of $\mathrm{Nb}$ on the surface compared to the from weighed portion expected $10 \%$ bulk concentration. This suggests the segregation of $\mathrm{Nb}$ at the surface of electrospun $\mathrm{TiO}_{2}$ fibers. According to the literature it is mainly the oxygen activity and oxygen affinity of the dopant that determines whether or not surface segregation occurs. ${ }^{52,53}$ The possibility of inhomogeneous $\mathrm{Nb}$ dopant distribution is not considered since the high solubility of $\mathrm{Nb}$ in $\mathrm{TiO}_{2}$ is widely known. ${ }^{44,54,55}$ 


\section{Theoretical and experimental XAS}

The Ti K-edge X-ray absorption near edge spectroscopy (XANES) spectra (4966 eV) of non-doped and $\mathrm{Nb}$-doped $\mathrm{TiO}_{2}$ are shown in Fig. 6. The absorption spectra reveal great resemblance, having the same number of pre-edge and edge features peaks and absorption edge position, merely small differences in intensity are observed. This is in good agreement with results from DFT calculations of the XAS spectra which illustrate that no significant changes of the Ti K-edge are expected under the influence of $\mathrm{Nb}$ doping, see Fig. 7. The observed differences between the relative amplitudes of the experimental and theoretical edge features are mainly due to energy dependent broadening effects caused by finite lifetime of the final electronic state which was not taken into account in the calculations for simplicity.

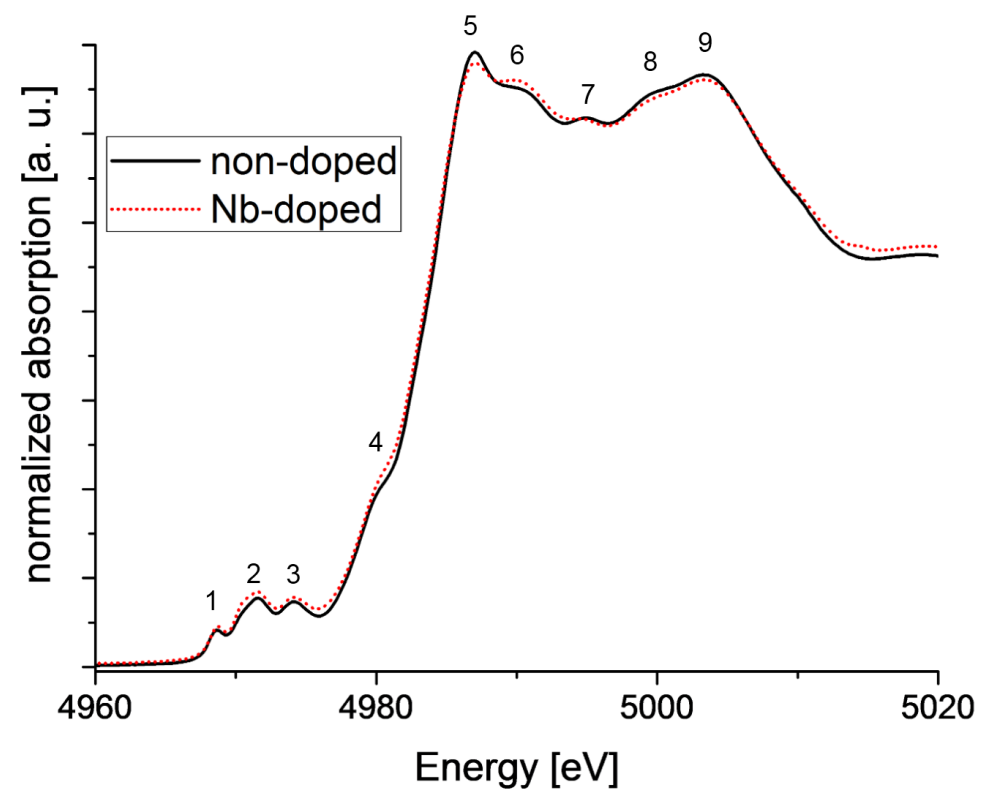

Figure 6: Measured Ti K-edge of XANES spectra of non-doped and $\mathrm{Nb}$-doped $\mathrm{TiO}_{2}$.

All the peaks of the experimental XANES spectra are reproduced by the calculations and can be assigned to main peaks of the Ti p DOS of the conduction band except for the pre-edge peak 1 which is purely quadrupolar as in the case of rutile $\mathrm{TiO}_{2} .{ }^{56}$ The pre-edge peaks 2 and 3 contain the dipolar components and reflect the $\mathrm{t}_{2 g}-\mathrm{e}_{g}$ splitting of $\mathrm{Ti}$ in $\mathrm{TiO}_{6}$ octahedral environment.

Since the comparison of XANES at the Ti K-edge of non-doped and Nb-doped anatase provides little information on the incorporation of $\mathrm{Nb}$ within the anatase lattice, we turned our attention to 

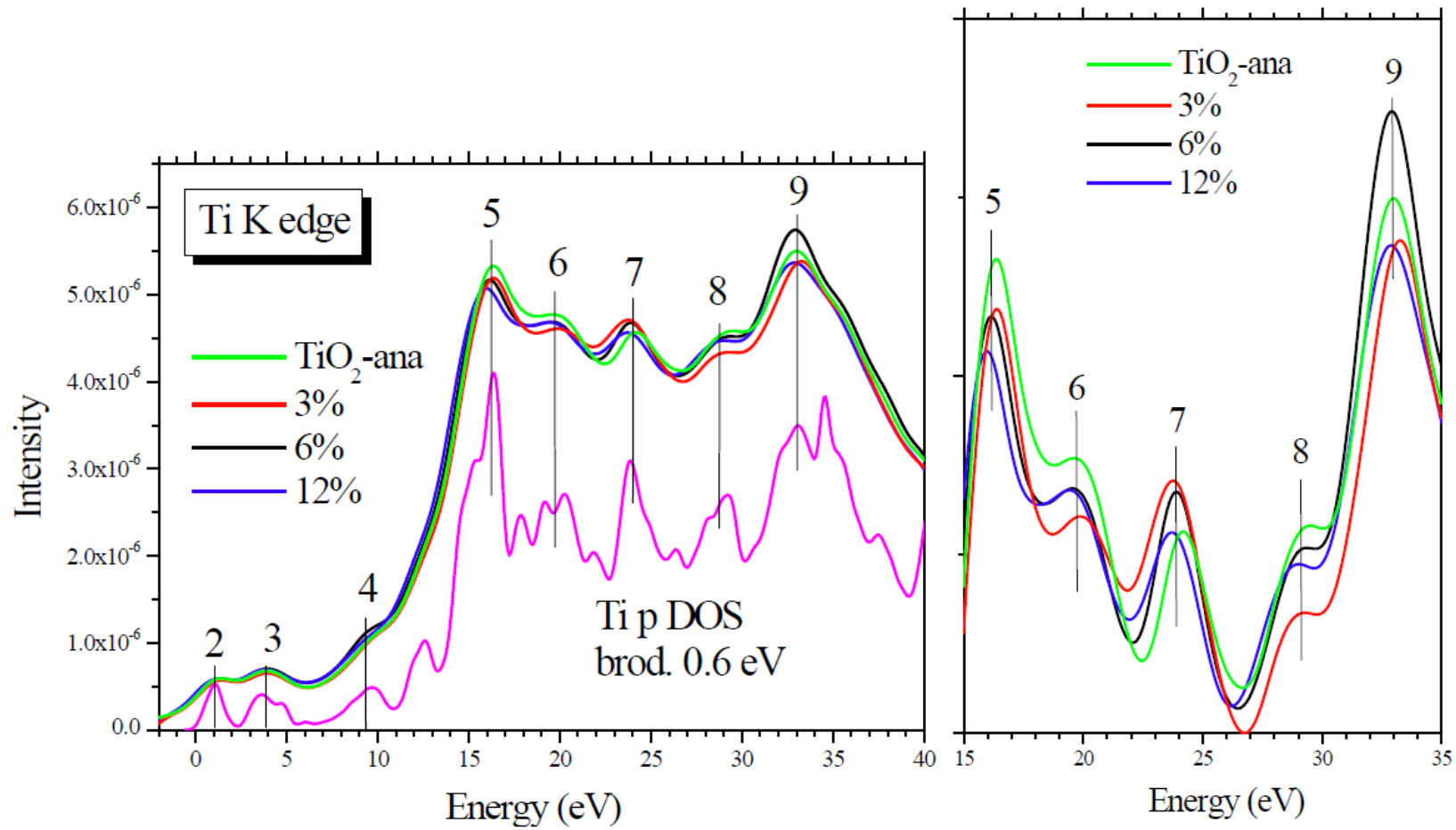

Figure 7: Theoretical XANES spectra at K-edge of non-doped and Nb-doped anatase $\mathrm{TiO}_{2}$ (about 3, 6 and 12 at. \% of $\mathrm{Nb}$ ). The broadened Ti p DOS is shown for comparison. The origin of energy is taken at the Fermi level.

the EXAFS signal which bears information on local structure. The $k^{2}$ weighted EXAFS signal of doped and non-doped $\mathrm{TiO}_{2}$ is shown in Fig. 8(a), and the derived Fourier transforms in Fig. 8(b). The spectra of non-doped and $\mathrm{Nb}$-doped $\mathrm{TiO}_{2}$ are rather similar, indicating that local structure is largely preserved. Only a slight decrease of the amplitude of the EXAFS spectrum of the Nb-doped sample is observed,corresponding to a slight decrease of the maxima in the Fourier transform, cf. Fig. 8(b).

According to the crystal structure of anatase, these spectra were fitted in the R-space using one oxygen coordination shell for the closest peak, and two titanium and one oxygen shell for the following ones. For the $\mathrm{Nb}$-doped sample, $\mathrm{Nb}$ incorporation in the anatase lattice was taken into account through a combination of the FEFF Ti-Ti paths of anatase and corresponding Ti-Nb paths derived from $\mathrm{Nb}_{2} \mathrm{O}_{5}$ in which central $\mathrm{Nb}$ atom was replaced by Ti. A slight variation of interatomic distances is observed upon $\mathrm{Nb}$ insertion (cf. Tab. 1) which suggests that $\mathrm{Nb}$ predominately occupies Ti sites. Furthermore, slightly higher Debye-Waller factors are observed for Nb-doped than 

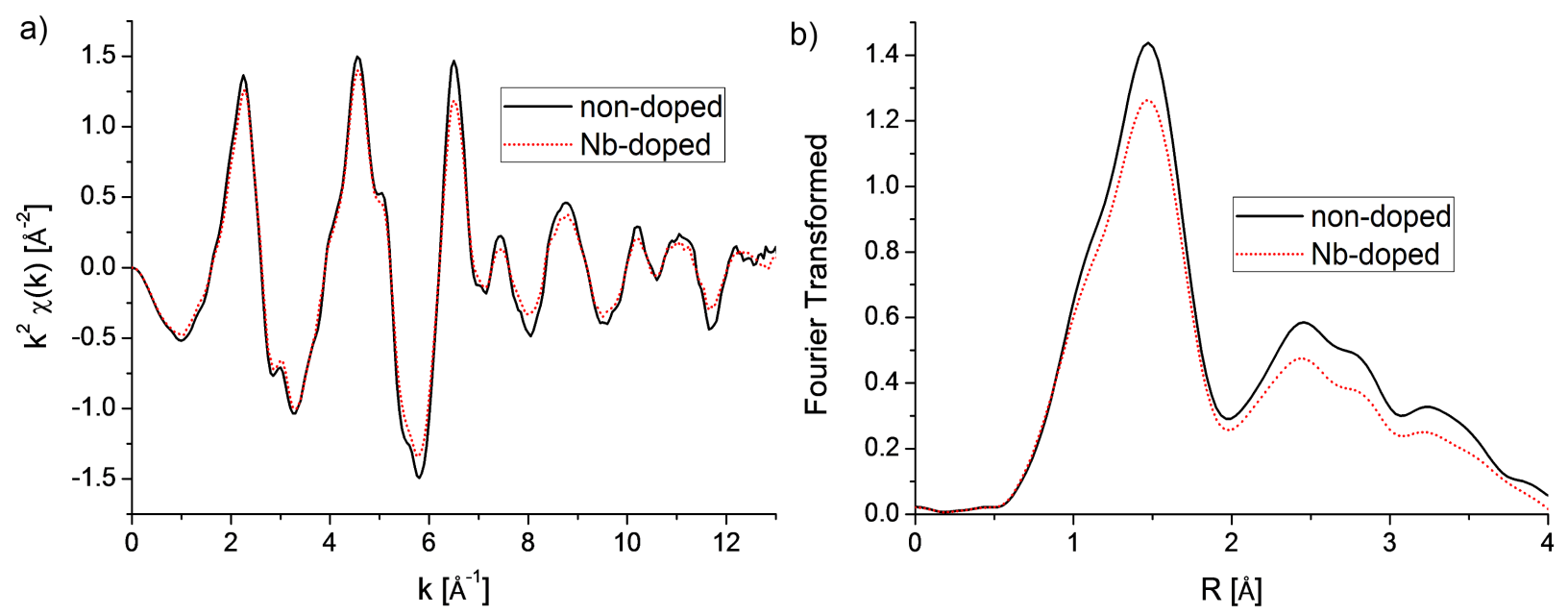

Figure 8: $K^{2}$ weighted a) EXAFS signal and b) Fourier transformed of non-doped and doped $\mathrm{TiO}_{2}$ nanofibers. The latter revealing position of next neighbor shells of central Ti atom for $\mathrm{Nb}$-doped and non-doped $\mathrm{TiO}_{2}$.

for non-doped $\mathrm{TiO}_{2}$, which reflects an increase in disorder of the structure due to incorporation of $\mathrm{Nb}$ in the anatase lattice. This explains the reduced intensity of the FT spectra of the doped sample, and confirms the substitutional doping of $\mathrm{Nb}$.

Table 1: EXAFS Fitting Parameters for non-doped and 10\% Nb-doped anatase

\begin{tabular}{|c|c|c|c|c|c|c|}
\hline & \multirow{2}{*}{ atom } & \multirow[t]{2}{*}{$\mathrm{CN}$} & \multicolumn{2}{|c|}{ interatomic distance $[\AA]$} & \multicolumn{2}{|c|}{ Debye-Waller factor $[\AA]^{2}$} \\
\hline & & & non-doped & Nb-doped & non-doped & Nb-doped \\
\hline 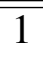 & $\overline{\mathrm{O}}$ & $\overline{6} 6$ & $1.948( \pm 0.005)$ & $1.949( \pm 0.004)$ & $0.0055( \pm 0.0006)$ & $0.0069( \pm 0.0006)$ \\
\hline 2 & $\mathrm{Ti} / \mathrm{Nb}$ & 4 & $3.068( \pm 0.007)$ & $3.068( \pm 0.007)$ & $0.0066( \pm 0.0009)$ & $0.0067( \pm 0.0009)$ \\
\hline 3 & $\mathrm{Ti} / \mathrm{Nb}$ & 4 & $3.88( \pm 0.10)$ & $3.85( \pm 0.08)$ & $0.023( \pm 0.022)$ & $0.020( \pm 0.024)$ \\
\hline 4 & $\mathrm{O}$ & 8 & $3.844( \pm 0.034)$ & $3.86( \pm 0.06)$ & $0.004( \pm 0.003)$ & $0.007( \pm 0.004)$ \\
\hline
\end{tabular}

The R-factor reflects the absolute misfit between experimental data and the fitted curve. Its variation as a function of the degree of $\mathrm{Nb}$ doping imposed during the fitting procedure follow a stretched parabolic slope with a minimum at $22 \mathrm{at} \% \mathrm{Nb}$ dopant, indicating the best agreement between measured and fitted EXAFS data, see Fig. 9. This result is in line with the assumption that $\mathrm{Nb}$ partially substitutes $\mathrm{Ti}$ atoms in the anatase lattice whereas the deviation of the peak minimum $(\approx 22 a t \%)$ from the expected $\mathrm{Nb}$-content $(\approx 10 \mathrm{at} \%)$ is considered acceptable regarding the width of the minimum and assumptions and simplifications made in the computational approach. 


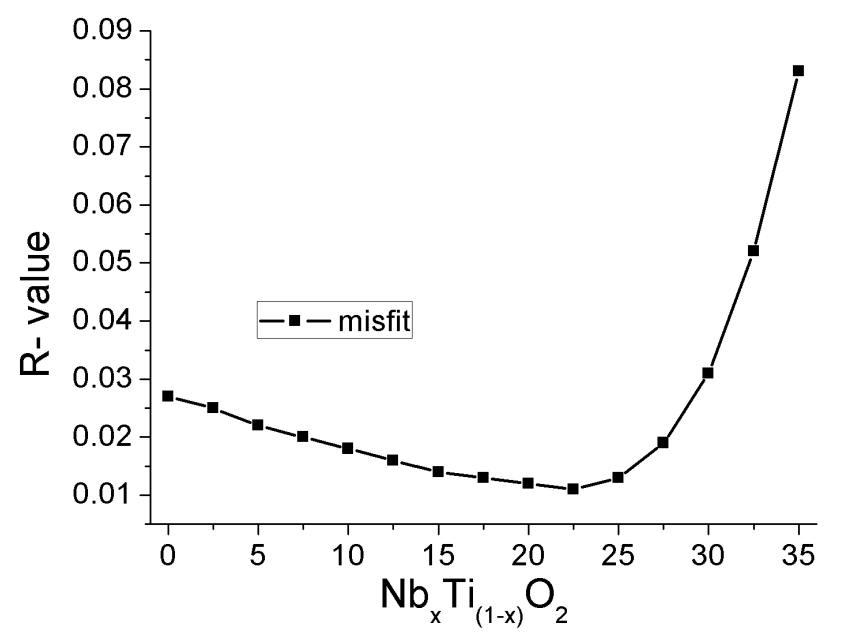

Figure 9: Misfit of EXAFS fit as function of extent of $\mathrm{Nb}$ doping of $\mathrm{TiO}_{2}$

\section{Electronic structure}

The partial density of states (PDOS) of $\mathrm{Nb} 4 \mathrm{~d}$ and $\mathrm{Ti} 3 \mathrm{~d}$ are similar, but the additional $\mathrm{Nb} 4 \mathrm{~d}$ electron (compared to the Ti $3 \mathrm{~d}$ electron number) pushes the Fermi level from the top of the valence band for non-doped $\mathrm{TiO}_{2}$ to the bottom of the conduction band for Nb-doped $\mathrm{TiO}_{2}$, Fig.10. The lowest $\mathrm{Nb} 4 \mathrm{~d}$ empty states are not in the band gap but overlap with Ti $3 \mathrm{~d}$ empty states to form a band in the range $0-2 \mathrm{eV}$. The Fermi level is located within this band, which indicates that $\mathrm{Nb}-$ doped anatase $\mathrm{TiO}_{2}$ has a metallic conductivity due to the delocalization of this additional $\mathrm{Nb} 4 \mathrm{~d}$ electron as previously discussed. ${ }^{33,34,44,46,57}$

Summing up the above stated findings we can assume that the main reason for the improved rate capability of $\mathrm{Nb}$-doped $\mathrm{TiO}_{2}$ lies in the enhancement of charge transfer in $\mathrm{TiO}_{2}$. Substituting $\mathrm{Ti}^{+4}$ by aliovalent $\mathrm{Nb}^{+5}$ introduces additional charge carries which improve the low bulk conductivity of $\mathrm{TiO}_{2}$. This effect is especially prominent at elevated cycling rates as kinetic limitations become more salient. Our results are very much in agreement with findings by Han et al. ${ }^{31}$ reporting a doubling of rate capability at increased cycling rate while absolute capacities are only slightly improved for aliovalent doped $\mathrm{TiO}_{2}$ electrospun fibers. The possibilities to compare our results to those of other groups are however limited as few groups focus on studying the isolated effect of the dopant like we did. In most existing studies side contributions deriving from complex syn- 


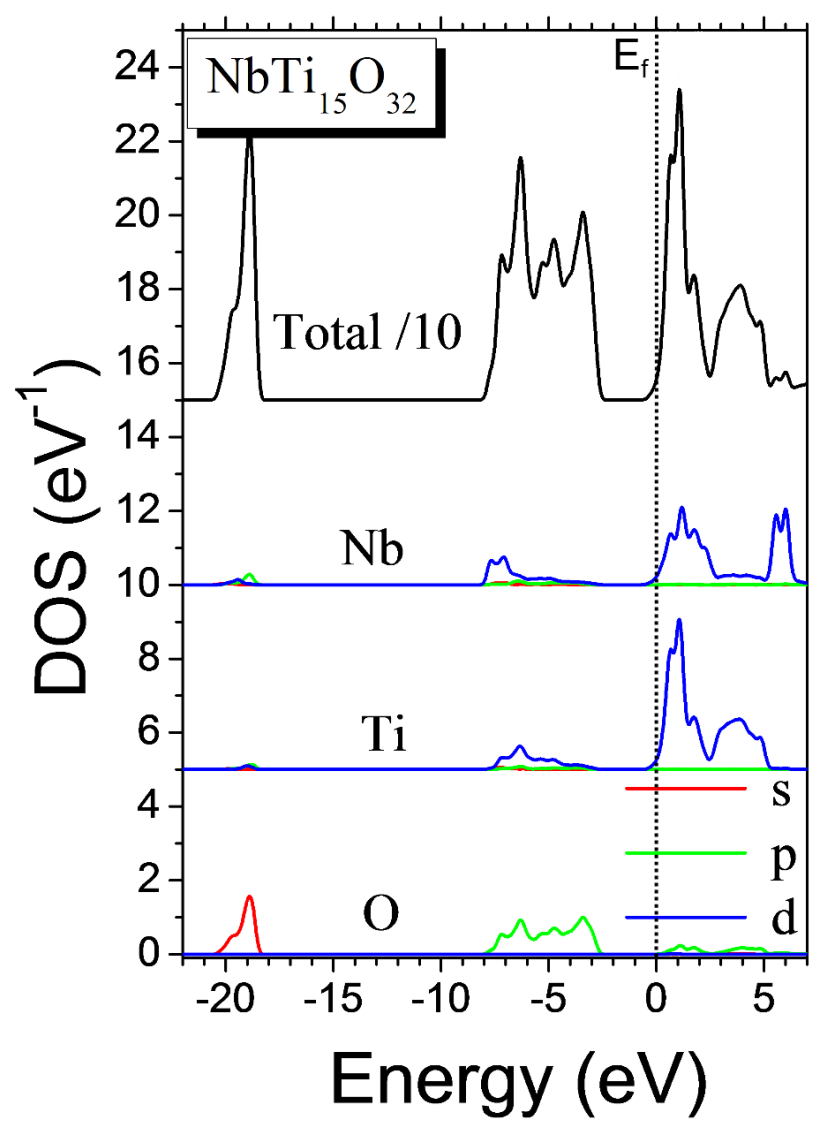

Figure 10: Calculated partial densities of states of $\mathrm{NbTi}_{15} \mathrm{O}_{32}(\approx 6 a t \%)$. The origin of energy is taken at the Fermi level (dotted line)

thesis method to achieve specific morphology $26,32,58,59$ or elaborate electrode formulation ${ }^{20,60-62}$ are superimposing to the effect of dopant and are therefore hardly comparable to our results. It is needless to say that a specific work on electrode formulation will probably bring rate capability and capacity retention improvements.

\section{Conclusions}

We showed that the $\mathrm{Nb}$ dopant is homogeneously distributed within the electrospun anatase fibers, and it is embedded in the lattice by substituting Ti. The statistical substitution of every tenth $\mathrm{Ti}$ atom by $\mathrm{Nb}$ has no influence on the global morphology and only slight changes of the lattice were observed via XRD and Raman. DFT calculations and XAS experimental results go hand in hand in showing that no relevant changes of Ti $\mathrm{K}$ absorption edge occur. EXAFS indicates an increased 
disorder in doped samples which underlines the embedding of $\mathrm{Nb}$ by substitutional doping in the bulk of $\mathrm{TiO}_{2}$. Galvanostatic cycling shows that the $\mathrm{Li}$ insertion mechanism remains largely unaffected by niobium doping of $\mathrm{TiO}_{2}$ anatase. However when comparing the rate capability, superior performance of $\mathrm{Nb}$-doped sample is evident. We ascribe this improvement predominantly to two of the observed $\mathrm{Nb}$-doping induced effects; Firstly the global increase in the electronic conductivity which is related to the change in Fermi level position and secondly the decrease in crystal size that is beneficial for interparticle contact and reduces diffusion paths, which is crucial for high performance cycling. The ancillary effect of increasing specific surface area is likely to also contribute to the observed improvement.

\section{Acknowledgments}

The authors are grateful for financial support by Saft and CNRS. Access to synchrotron radiation facilities of ELETTRA (XAFS beamline) and Desy (Beamline A) is acknowledged. The authors would like to thank Luca Olivi, Giuliana Aquilanti and Edmund Welter for expert advice on beamline operation. Furthermore the research leading to these results has received funding from the European Research Council under the European Union's Seventh Framework Programme (FP/2007-2013) / ERC Grant Agreement n. 306682.

\section{References}

(1) Yoshino, A. The Birth of the Lithium-Ion Battery. Angewandte Chemie 2012, 51, 5798-5800.

(2) Deng, D.; Kim, M. G.; Lee, J. Y.; Cho, J. Green energy storage materials: Nanostructured TiO2 and Sn-based anodes for lithium-ion batteries. Energy Environ. Sci. 2009, 2, 818-837.

(3) Kerisit, S.; Rosso, K. M.; Yang, Z.; Liu, J. Dynamics of Coupled Lithium/Electron Diffusion in TiO2 Polymorphs. J. Phys. Chem. C 2009, 113, 20998-21007.

(4) Kyeremateng, N.; Vacandio, F.; Sougrati, M.-T.; Martinez, H.; Jumas, J.-C.; Knauth, P.; Dj- 
enizian, T. Effect of Sn-doping on the electrochemical behaviour of $\mathrm{TiO} 2$ nanotubes as potential negative electrode materials for 3D Li-ion micro batteries. Journal of Power Sources 2013, 224, 269-277.

(5) Nowotny, J. In Oxide Semiconductors for Solar Energy Conversion TiO2; Sunggyu Lee,, Ed.; CRC Press: Boca Raton, Fl, 2012; p 414.

(6) Shin, J.-y.; Joo, J. H.; Samuelis, D.; Maier, J. Oxygen-Deficient TiO2ấL Š $\delta$ Nanoparticles via Hydrogen Reduction for High Rate Capability Lithium Batteries. Chem. Mater. 2012, 24, $543-551$.

(7) Xia, Y.; Yang, P.; Sun, Y.; Wu, Y.; Mayers, B.; Gates, B.; Yin, Y.; Kim, F.; Yan, H. OneDimensional Nanostructures: Synthesis, Characterization, and Applications. Advanced Materials 2003, 15, 353-389.

(8) Barth, S.; Hernandez-Ramirez, F.; Holmes, J. D.; Romano-Rodriguez, A. Synthesis and applications of one-dimensional semiconductors. Progress in Materials Science 2010, 55, 563627.

(9) Cheng, F.; Tao, Z.; Liang, J.; Chen, J. Template-Directed Materials for Rechargeable LithiumIon Batteries. Chem. Mater. 2008, 20, 667-681.

(10) Tarascon, J.-M.; Recham, N.; Armand, M.; Chotard, J.-N.; Barpanda, P.; Walker, W.; Dupont, L. Hunting for Better Li-Based Electrode Materials via Low Temperature Inorganic Synthesis. Chem. Mater. 2010, 22, 724-739.

(11) Kasuga, T.; Hiramatsu, M.; Hoson, A.; Sekino, T. Formation of titanium oxide nanotube. Langmuir 1998, 7463, 3160-3163.

(12) Zhao, B.; Shao, Z. From Paper to Paper-Like Hierarchical Anatase TiO 2 Film Electrode for High-Performance Lithium-Ion Batteries. The Journal of Physical Chemistry C 2012, 116, $17440-17447$. 
(13) Reneker, D.; Yarin, A.; Zussman, E.; Xu, H. Electrospinning of nanofibers from polymer solutions and melts. Advances in Applied Mechanics 2007, 41, 44-197.

(14) Sawicka, K. M.; Gouma, P. Electrospun composite nanofibers for functional applications. Journal of Nanoparticle Research 2006, 8, 769-781.

(15) Dai, Y.; Liu, W.; Formo, E.; Sun, Y.; Xia, Y. Ceramic nanofibers fabricated by electrospinning and their applications in catalysis, environmental science, and energy technology. Polymers for Advanced Technologies 2011, 22, 326-338.

(16) Cavaliere, S.; Subianto, S.; Savych, I.; Jones, D. J.; Rozière, J. Electrospinning: designed architectures for energy conversion and storage devices. Energy \& Environmental Science 2011, 4, 4761-4785.

(17) Cavaliere, S.; Subianto, S.; Chevallier, L.; Jones, D. J.; Rozière, J. Single step elaboration of size-tuned Pt loaded titania nanofibres. Chemical Communications 2011, 47, 6834-6836.

(18) Bauer, A.; Chevallier, L.; Hui, R.; Cavaliere, S.; Zhang, J.; Jones, D.; Rozière, J. Synthesis and characterization of $\mathrm{Nb}-\mathrm{TiO} 2$ mesoporous microsphere and nanofiber supported $\mathrm{Pt}$ catalysts for high temperature PEM fuel cells. Electrochimica Acta 2012, 77, 1-7.

(19) Luo, W.; Hu, X.; Sun, Y.; Huang, Y. Surface modification of electrospun TiO2 nanofibers via layer-by-layer self-assembly for high-performance lithium-ion batteries. Journal of Materials Chemistry 2012, 22, 4910-4915.

(20) Zhu, P.; Wu, Y.; Reddy, M. V.; Sreekumaran Nair, A.; Chowdari, B. V. R.; Ramakrishna, S. Long term cycling studies of electrospun $\mathrm{TiO} 2$ nanostructures and their composites with MWCNTs for rechargeable Li-ion batteries. RSC Advances 2012, 2, 531-537.

(21) Yang, X.; Teng, D.; Liu, B.; Yu, Y.; Yang, X. Nanosized anatase titanium dioxide loaded porous carbon nanofiber webs as anode materials for lithium-ion batteries. Electrochemistry Communications 2011, 13, 1098-1101. 
(22) Feng, C.; Tang, J.; Zhang, C.; Zeng, R. Synthesis and Electrochemical Properties of TiO2/C Nano-Fiber Composite. Nanoscience and Nanotechnology Letters 2012, 4, 430-434.

(23) Zhang, X.; Kumar, P. S. Electrospun TiO2-Graphene Composite Nanofibers as Highly Durable Insertion Anode for Lithium-Ion Batteries. The Journal of Physical Chemistry C 2012, 116, 14780-14788.

(24) Manthiram, A.; Vadivel Murugan, A.; Sarkar, A.; Muraliganth, T. Nanostructured electrode materials for electrochemical energy storage and conversion. Energy \& Environmental Science 2008, 1, 621-638.

(25) Nam, S. H.; Shim, H.-S.; Kim, Y.-S.; Dar, M. A.; Kim, J. G.; Kim, W. B. Ag or Au Nanoparticle-Embedded One-Dimensional Composite TiO2 Nanofibers Prepared via Electrospinning for Use in Lithium-Ion Batteries. ACS Appl. Mater. Interfaces 2010, 2, 20462052.

(26) Yuan, T.; Zhao, B.; Cai, R.; Zhou, Y.; Shao, Z. Electrospinning based fabrication and performance improvement of film electrodes for lithium-ion batteries composed of $\mathrm{TiO} 2$ hollow fibersâĂă. Journal of Materials Chemistry 2011, 21, 15041-15048.

(27) Jin, M.; Zhang, X.; Pu, H.; Nishimoto, S.; Murakami, T.; Fujishima, A. Photochromismbased detection of volatile organic compounds by $\mathrm{W}$-doped $\mathrm{TiO}(2)$ nanofibers. Journal of Colloid and Interface Science 2011, 362, 188-93.

(28) Babu, V. J.; Nair, A. S.; Peining, Z.; Ramakrishna, S. Synthesis and characterization of rice grains like, Nitrogen-doped $\mathrm{TiO} 2$ nanostructures by electrospinning-photocatalysis. Materials Letters 2011, 65, 3064-3068.

(29) Park, J.-Y.; Lee, J.-H.; Choi, D.-Y.; Hwang, C.-H.; Lee, J.-W. Influence of Fe doping on phase transformation and crystallite growth of electrospun $\mathrm{TiO} 2$ nanofibers for photocatalytic reaction. Materials Letters 2012, 88, 156-159. 
(30) Bingham, S.; Daoud, W. a. Recent advances in making nano-sized TiO2 visible-light active through rare-earth metal doping. Journal of Materials Chemistry 2011, 21, 2041-2050.

(31) Han, H.; Song, T.; Bae, J.-Y.; Nazar, L. F.; Kim, H.; Paik, U. Nitridated TiO2 hollow nanofibers as an anode material for high power lithium ion batteries. Energy \& Environmental Science 2011, 4, 4532-4536.

(32) Wang, Y.; Smarsly, B. M.; Djerdj, I. Niobium Doped TiO2 with Mesoporosity and Its Application for Lithium Insertion. Chemistry of Materials 2010, 22, 6624-6631.

(33) Archana, P. S.; Jose, R.; Jin, T. M.; Vijila, C.; Yusoff, M. M.; Ramakrishna, S. Structural and Electrical Properties of Nb-Doped Anatase TiO2 Nanowires by Electrospinning. Journal of the American Ceramic Society 2010, 93, 4096-4102.

(34) Sheppard, L. R.; Bak, T.; Nowotny, J. Electrical properties of niobium-doped titanium dioxide. 1. Defect disorder. The Journal of Physical Chemistry B 2006, 110, 22447-22454.

(35) Perdew, J.; Burke, K.; Ernzerhof, M. Generalized Gradient Approximation Made Simple. Physical Review Letters 1996, 77, 3865-3868.

(36) Blaha, P.; Schwarz, K.; Madsen, G.; Kvasnicka, D.; Luitz, J. WIEN2K An augmented plane wave plus local orbitals program for calculating crystal properties. 2001.

(37) Weibel, A.; Bouchet, R.; Savin, S. L. P.; Chadwick, A. V.; Lippens, P. E.; Womes, M.; Knauth, P. Local atomic and electronic structure in nanocrystalline Sn-doped anatase TiO2. ChemPhysChem 2006, 7, 2377-2383.

(38) Lippens, P.; Chadwick, A. Structure and chemical bonding in Zr-doped anatase TiO2 nanocrystals. The Journal of Physical Chemistry C 2008, 112, 43-47.

(39) Lippens, P.-E.; Womes, M.; Kubiak, P.; Jumas, J.-C.; Olivier-Fourcade, J. Electronic structure of the spinel Li4Ti5O12 studied by ab initio calculations and X-ray absorption spectroscopy. Solid State Sciences 2004, 6, 161-166. 
(40) An, H.; Ahn, H.-J. Fabrication of wrinkled Nb-doped TiO2 nanofibres via electrospinning. Materials Letters 2013, 93, 88-91.

(41) Sing, K. S. W. Reporting Physisoprtion Data for Gas/Solid Systems with Special Reference to the Determination of Surface Area and Porosity. Pure Appl. Chem. 1982, 54, 2201-2218.

(42) Ruiz, A. M.; Dezanneau, G.; Arbiol, J.; Cornet, A.; Morante, J. R. Insights into the Structural and Chemical Modifications of $\mathrm{Nb}$ Additive on TiO2 Nanoparticles. Chem. Mater. 2004, 16, 862-871.

(43) Guidi, V.; Carotta, M. Effect of dopants on grain coalescence and oxygen mobility in nanostructured titania anatase and rutile. The Journal of Physical Chemistry B 2003, 107, 120-124.

(44) Furubayashi, Y.; Hitosugi, T.; Yamamoto, Y.; Inaba, K.; Kinoda, G.; Hirose, Y.; Shimada, T.; Hasegawa, T. A transparent metal: Nb-doped anatase TiO2. Applied Physics Letters 2005, $86,252101-3$.

(45) Hirano, M.; Ichihashi, Y. Phase transformation and precipitation behavior of niobium component out of niobium-doped anatase-type $\mathrm{TiO} 2$ nanoparticles synthesized via hydrothermal crystallization. Journal of Materials Science 2009, 44, 6135-6143.

(46) Yang, Z.; Choia, D.; Kerisit, S.; Rosso, K. M.; Wang, D.; Zhang, J.; Graff, G.; Liu, J. Nanostructures and lithium electrochemical reactivity of lithium titanites and titanium oxides: A review. J. Power Sources 2009, 192, 588-598.

(47) Baddour-Hadjean, R.; Pereira-Ramos, J.-P. Raman Microspectrometry Applied to the Study of Electrode Materials for Lithium Batteries. Chem. Rev. 2010, 110, 1278-1319.

(48) Lejon, C.; Österlund, L. Influence of phonon confinement, surface stress, and zirconium doping on the Raman vibrational properties of anatase $\mathrm{TiO} 2$ nanoparticles. Journal of Raman Spectroscopy 2011, 42, 2026-2035. 
(49) Kuznetsov, M. V.; Zhuravlev, J. F.; Zhilyaev, V. A.; Gubanov, V. A. XPS study of the nitrides, oxides and oxynitrides of titanium. Journal of Electron Spectroscopy and Related Phenomena $1 \mathbf{1 9 9 2 , 5 8 , 1 - 9 .}$

(50) Bahl, M. ESCA studies of some niobium compounds. Journal of Physics and Chemistry of Solids 1975, 36, 485-491.

(51) Wang, P.; Wu, J.; Ao, Y.; Wang, C.; Hou, J.; Qian, J. Preparation and enhanced photocatalytic performance of Sn ion modified titania hollow spheres. Materials Letters 2011, 65, 32783280 .

(52) Sheppard, L. R.; Dittrich, T.; Nowotny, M. K. The Impact of Niobium Surface Segregation on Charge Separation in Niobium-Doped Titanium Dioxide. The Journal of Physical Chemistry C 2012, 116, 20923-20929.

(53) Ehinon, K. K. D.; Naille, S.; Dedryve, R.; Lippens, P. E.; Jumas, J.-C.; Gonbeau, D. Ni 3 Sn 4 Electrodes for Li-Ion Batteries : Li-Sn Alloying Process and Electrode / Electrolyte Interface Phenomena. Chem. Mater. 2008, 20, 5388-5398.

(54) Knauth, P.; Chadwick, A. V.; Lippens, P. E.; Auer, G. EXAFS study of dopant ions with different charges in nanocrystalline anatase: evidence for space-charge segregation of acceptor ions. ChemPhysChem 2009, 10, 1238-46.

(55) Bouchet, R.; Weibel, A.; Knauth, P. EXAFS study of dopant segregation (Zn, Nb) in nanocrystalline anatase (TiO2). Chemistry of Materials 2003, 15, 4996-5002.

(56) Joly, Y.; Cabaret, D.; Renevier, H.; Natoli, C. Electron Population Analysis by Full-Potential X-Ray Absorption Simulations. Physical Review Letters 1999, 82, 2398-2401.

(57) Hitosugi, T.; Kamisaka, H.; Yamashita, K.; Nogawa, H.; Furubayashi, Y.; Nakao, S.; Yamada, N.; Chikamatsu, A.; Kumigashira, H.; Oshima, M.; Hirose, Y.; Shimada, T.; 
Hasegawa, T. Electronic Band Structure of Transparent Conductor: Nb-Doped Anatase TiO2. Applied Physics Express 2008, 1, 111203-06.

(58) Ali, Z.; Cha, S. N.; Sohn, J. I.; Shakir, I.; Yan, C.; Kim, J. M.; Kang, D. J. Design and evaluation of novel $\mathrm{Zn}$ doped mesoporous $\mathrm{TiO} 2$ based anode material for advanced lithium ion batteries. Journal of Materials Chemistry 2012, 22, 17625.

(59) Das, S. K.; Gnanavel, M.; Patel, M. U. M.; Shivakumara, C.; Bhattacharyya, A. J. Anamolously High Lithium Storage in Mesoporous Nanoparticulate Aggregation of Fe3+ Doped Anatase Titania. Journal of The Electrochemical Society 2011, 158, A1290.

(60) Ding, Y.-H.; Zhang, P.; Ren, H.-M.; Zhuo, Q.; Yang, Z.-M.; Jiang, Y. Preparation of graphene/TiO2 anode materials for lithium-ion batteries by a novel precipitation method. Materials Research Bulletin 2011, 46, 2403-2407.

(61) Yang, Z.; Du, G.; Meng, Q.; Guo, Z.; Yu, X.; Chen, Z.; Guo, T.; Zeng, R. Synthesis of uniform TiO2@carbon composite nanofibers as anode for lithium ion batteries with enhanced electrochemical performance. Journal of Materials Chemistry 2012, 22, 5848.

(62) Cao, F.-F.; Xin, S.; Guo, Y.-G.; Wan, L.-J. Wet chemical synthesis of $\mathrm{Cu} / \mathrm{TiO} 2$ nanocomposites with integrated nano-current-collectors as high-rate anode materials in lithium-ion batteries. Physical chemistry chemical physics : PCCP 2011, 13, 2014-20. 

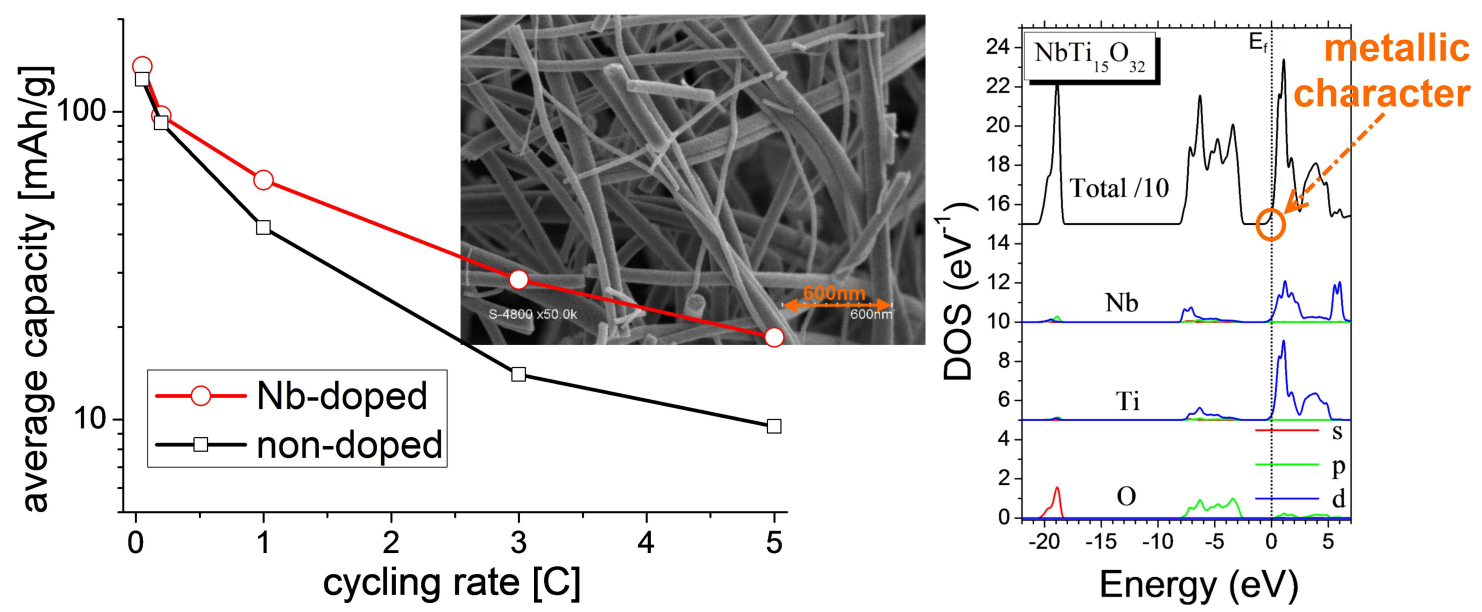

Figure 11: Table of Content figure 